\title{
RESEARCH
}

Open Access

\section{Surgery school-who, what, when, and how: results of a national survey of multidisciplinary teams delivering group preoperative education}

\author{
I. Fecher-Jones ${ }^{1 *}$ D, C. Grimmett ${ }^{2}$, F. J. Carter ${ }^{3}$, D. H. Conway ${ }^{4}$, D. Z. H. Levett ${ }^{1}$ and J. A. Moore ${ }^{4}$
}

\begin{abstract}
Background: Group education is increasing in popularity as a means of preparing patients for surgery. In recent years, these 'surgery schools' have evolved from primarily informing patients of what to expect before and after surgery, to providing support and encouragement for patients to 'prehabilitate' prior to surgery, through improving physical fitness, nutrition and emotional wellbeing.

Method: A survey aimed at clinicians delivering surgery schools was employed to capture a national overview of activity to establish research and practice priorities in this area. The survey was circulated online via the Enhanced Recovery after Surgery UK Society and the Centre for Perioperative Care mailing lists as well as social media.

Results: There were 80 responses describing 28 active and 4 planned surgery schools across the UK and Ireland. Schools were designed and delivered by multidisciplinary teams, contained broadly similar content and were well attended. Most were funded by the National Health Service. The majority included aspects of prehabilitation most commonly the importance of physical fitness. Seventy five percent of teams collected patient outcome data, but less than half collected data to establish the clinical effectiveness of the school. Few describe explicit inclusion of evidencebased behavior change techniques, but collaboration and partnerships with community teams, gyms and local charities were considered important in supporting patients to make changes in health behaviors prior to surgery.

Conclusion: It is recommended that teams work with patients when designing surgery schools and use evidencebased behavior change frameworks and techniques to inform their content. There is a need for high-quality research studies to determine the clinical effectiveness of this type of education intervention.
\end{abstract}

Keywords: Preoperative education, Surgery school, Prehabilitation, Perioperative medicine

\footnotetext{
* Correspondence: Imogen.fecher@uhs.nhs.uk

'University Hospital Southampton NHS Foundation Trust, Southampton SO16 6YD, UK

Full list of author information is available at the end of the article
}

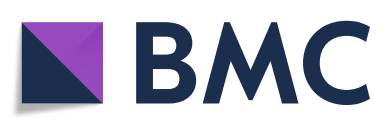

(- The Author(s). 2021 Open Access This article is licensed under a Creative Commons Attribution 4.0 International License, which permits use, sharing, adaptation, distribution and reproduction in any medium or format, as long as you give appropriate credit to the original author(s) and the source, provide a link to the Creative Commons licence, and indicate if changes were made. The images or other third party material in this article are included in the article's Creative Commons licence, unless indicated otherwise in a credit line to the material. If material is not included in the article's Creative Commons licence and your intended use is not permitted by statutory regulation or exceeds the permitted use, you will need to obtain permission directly from the copyright holder. To view a copy of this licence, visit http://creativecommons.org/licenses/by/4.0/. The Creative Commons Public Domain Dedication waiver (http://creativecommons.org/publicdomain/zero/1.0/) applies to the data made available in this article, unless otherwise stated in a credit line to the data. 
The average person in the UK will undergo four to six surgeries during their lifetime (Nepogodiev et al., 2019). Patient education prior to surgery is an established part of the surgical pathway, traditionally undertaken within presurgical clinics and focussing on what to expect. It is generally accepted that well-prepared patients are more confident and less anxious about undergoing surgery (Dawson, 2000). Despite established programmes in the USA since the 1970s (Mezzanotte, 1970), preoperative education in a group setting is a relatively new concept in the UK and Ireland with a primary focus on educating patients within Enhanced Recovery after Surgery (ERAS) programmes, particularly within orthopaedics. Reported outcomes have included reduction in length of hospital stay, reduced preoperative anxiety and reduced postoperative pain (Giraudet-Le Quintrec et al., 2003; McGregor et al., 2004).

The last 5 years have seen an evolution of 'surgery schools' within the UK and Ireland. The schools now not only prepare patients for what to expect, but also provide advice and support on what patients can do to prepare themselves physically and mentally to reduce the risk of postoperative complications (Moore et al., 2017; Moore et al., 2020). Improving physical fitness, nutrition and emotional wellbeing prior to surgery is known as 'Prehabilitation' and has been shown to improve surgical outcomes ( $\mathrm{Li}$ et al., 2013). To date prehabilitation interventions have primarily been limited to research trials. There is now emerging evidence that educating surgical patients in groups as part of a clinical service and using evidence-based behaviour change techniques may promote behaviour change, thus optimising physical and psychological health (Fecher-Jones et al., 2021).

Despite these 'Fit for Surgery' schools anecdotally growing in number and becoming a regular feature of perioperative conference agendas, clinical and patientreported outcomes of these interventions remain largely unreported. As leads for surgery schools at University Hospital Southampton and Manchester Royal Infirmary, we felt it timely to capture a national overview of surgery school development and activity. The aim was to identify similarities and differences in surgery schools across the UK and Ireland, including content, outcomes measured and funding mechanisms. The results would enable greater insight into the variations of this educational intervention and allow research and practice priorities to be identified.

\section{Methods}

A bespoke survey was conducted in the summer of 2019 aimed at health care teams delivering surgery schools (See Additional File 1).
The survey was designed using 'Survey Monkey' (Survey Monkey, 2019), an online survey platform. The link to the survey was initially sent out via email to all members of the ERAS UK society as a pilot to gauge responses, and following minor amendments was disseminated by the authors through social media (Twitter and Facebook) from 13/9/2019. Response rate was reviewed, and the survey sent out again by the UK Centre for Perioperative Care to all perioperative medicine leads. The survey was open for 94 days, closing on $16 / 12 / 2019$. Descriptive statistics were calculated for numeric survey items. Content analysis was used to analyse open responses and key themes identified.

\section{Results}

There were 80 responses to the survey, from 45 different hospitals. One respondent was excluded as they were from outside of the UK and Ireland and 11 others excluded as they were duplicate entries. Thirty-six respondents had significant missing data, providing job title and location only. Following exclusion of duplicated entries and missing data, there were 28 active surgery schools and four with planned start dates. For breakdown of responses see Fig. 1.

The active and planned schools were situated in 23 different National Health Service (NHS) Trusts with broad spread across England, Scotland and Wales and one in Dublin. There was no reply from colleagues in Northern Ireland. Some geographic areas such as London had more than one surgery school. One respondent who described an active school declined to enter their geographical location.

Over half of the respondents of active and planned schools were anaesthetists 24 (56\%), and 12 (28\%) nurses. The remaining six respondents were other members of the multidisciplinary team (MDT) including physiotherapists, occupational therapists and one surgeon.

\section{Surgery school design}

Respondents described a range of MDT members involved in the design and delivery of the 28 active and four planned schools (see Fig. 2). Most common professions involved in design were anaesthetists, nurses, physiotherapists and surgeons, with psychologists and patients in the minority. Over half of the responders $(66 \%(n=32))$ stated that their school was delivered or would be delivered by three or more members of the MDT. Most commonly, these included a nurse, physiotherapist and anaesthetist.

A small number $(11 \%(n=4))$ of surgery schools had been running for over a decade, most commonly in orthopaedics. Almost half $(43 \%(n=12))$ had started within the last 2years and reported finding it useful to visit 


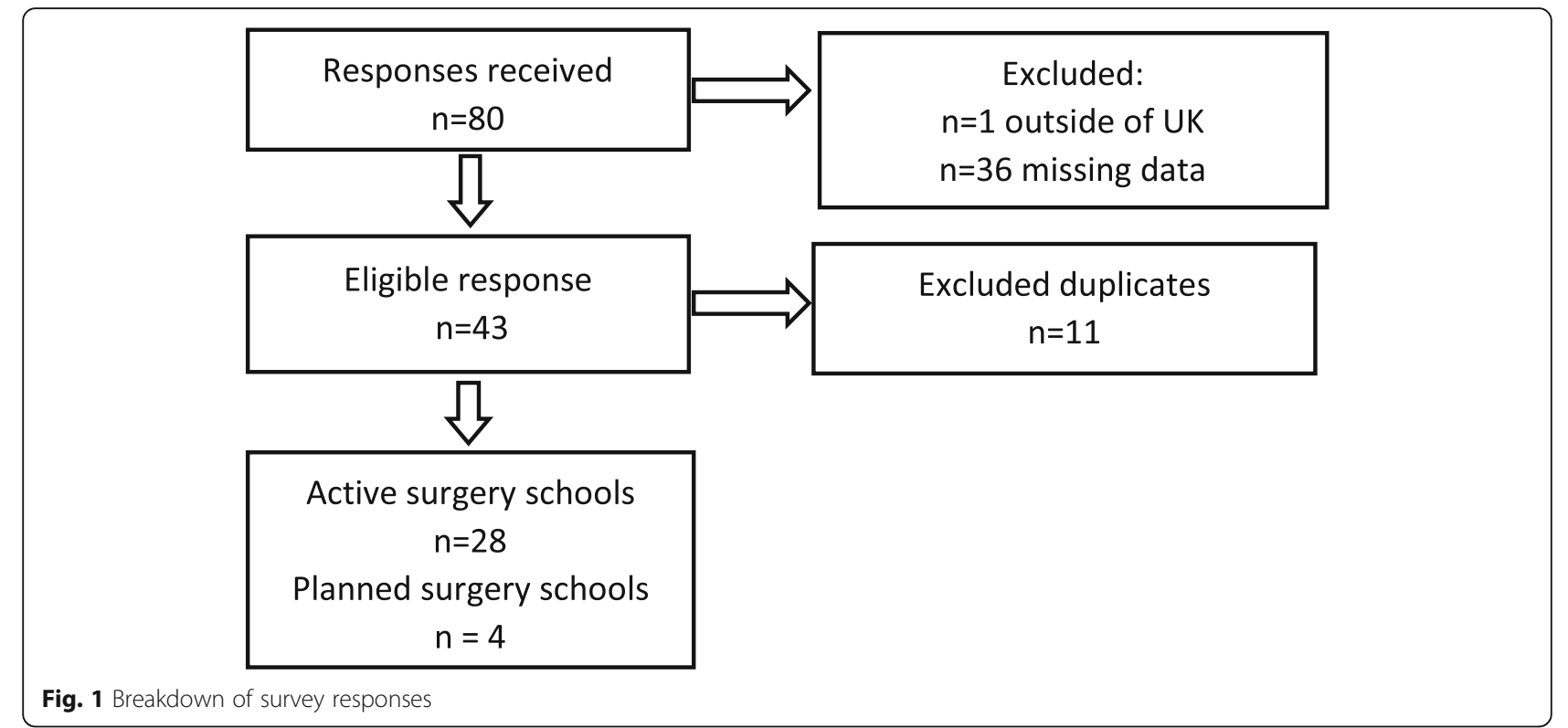

other hospitals running schools before setting up their own..

Most respondents $(71 \%(n=23))$ reported that their surgery schools were funded by their own NHS Trust. The remaining schools were funded by local partnerships, national grants and charities; two of the schools were unfunded and undertaken in staff members' own time. Almost half $(46 \%(n=15))$ reported that their funding was ongoing, $18 \%(n=6)$ reported fixed term funding and the remaining $24 \%(n=7)$ did not know their funding mechanism.

\section{Surgery school structure and content}

The majority of active surgery schools (71\% $(n=20))$ were reported as lasting 1 to $2 \mathrm{~h}$ and offered as a single session per patient $(85 \%(n=24))$, with between 5 and 20 patients $(82 \%(n=23))$ attending each school event. Three respondents stated that they had more than twenty patients attend at a time. Patient attendance was reported by $82 \%(n=23)$ of respondents and ranged from 35 to $100 \%$ of those invited, with the majority $(78 \%(n=22))$ reporting very good attendance rates of $80-100 \%$.

Active schools were being delivered to ten different surgical specialties, mostly commonly in orthopaedics, colorectal and urology (see Fig. 3). Orthopaedic schools $(n=12)$ were run exclusively for orthopaedic patients. The remaining schools apart from three colorectal schools were mixed specialty.

Eleven of the hospital teams (39\%) invited all their surgical patients undergoing major surgery to attend their surgery school as part of the surgical booking process, with three of those (11\%) stating that school attendance

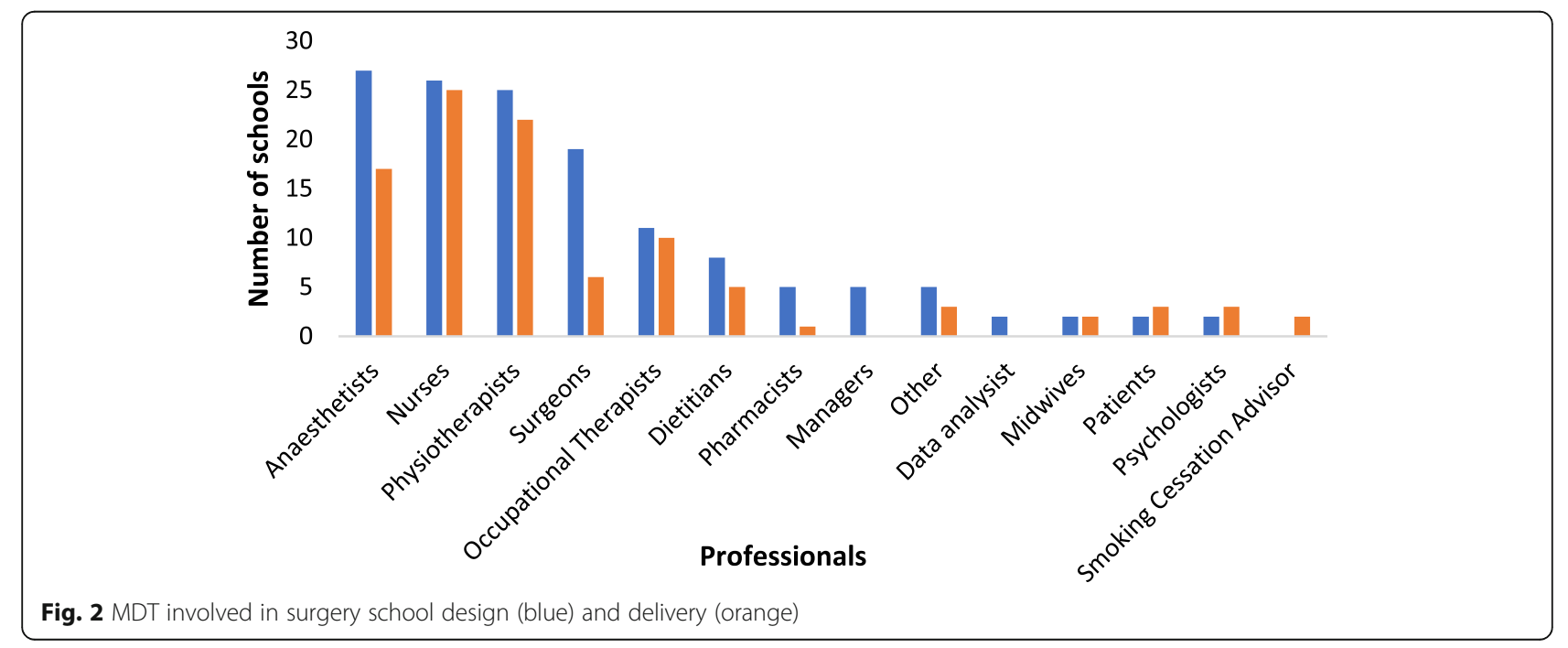




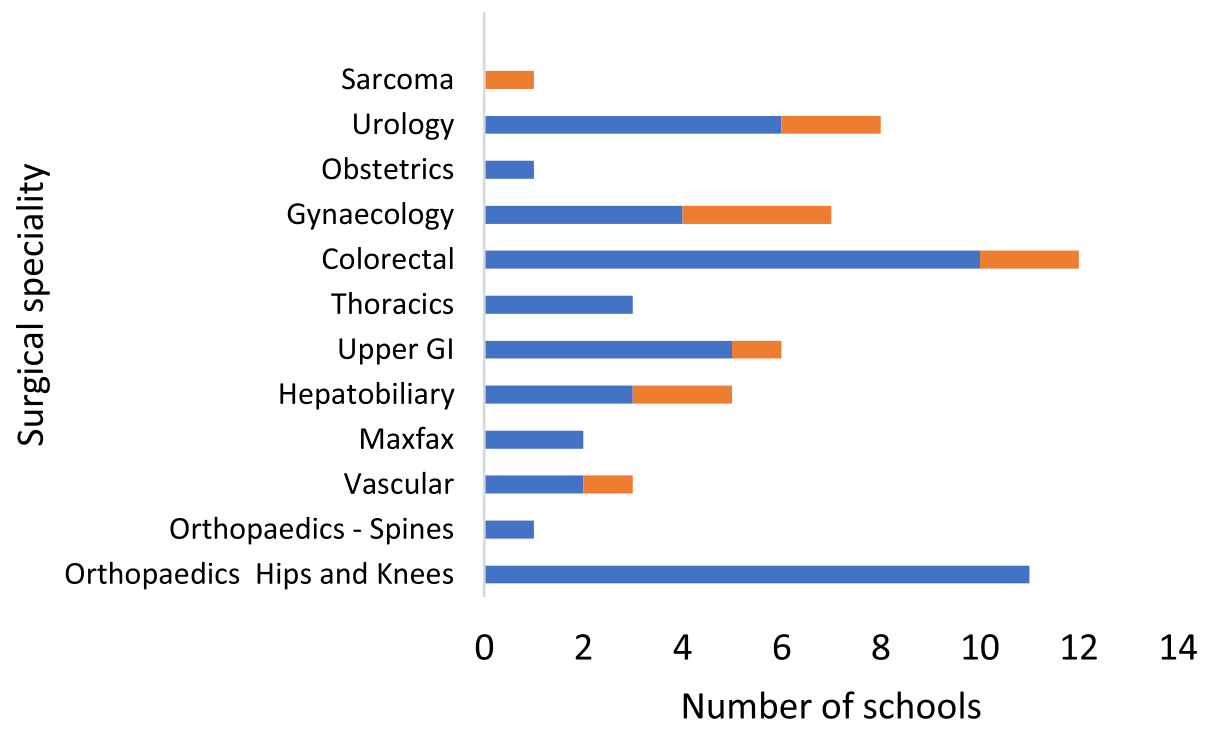

Fig. 3 Specialties invited to active surgery schools (blue), specialties to be invited to planned schools (orange)

was mandatory for patients prior to surgery. The remaining $61 \%(n=17)$ of active schools relied on case by case referrals from their surgeons, clinical nurse specialists and preoperative teams.

\section{Taught content}

The active and planned schools covered a range of topics. Most commonly taught were what to expect coming into hospital, enhanced recovery principles, increasing physical fitness, rehabilitation exercises and smoking cessation. Only half of the schools taught postoperative breathing exercises, and less than half described specific content to support emotional wellbeing (see Fig. 4). Other topics included stoma care training, pain control and the role of therapy services in recovery.
Almost all respondents $(96 \%(n=31))$ reported using supporting resources alongside their face-to-face teaching; most commonly used $(75 \%(n=24))$ were bespoke locally designed patient information leaflets; only $19 \%(n=6)$ used national written patient information. Almost half of the schools sign-posted to online resources $(47 \%(n=15)$, videos and DVDS were used by $41 \% \quad(n=13))$, and less commonly Apps $(13 \%(n=$ 4)), DVDs, apps and signposting to online resources.

The majority of active and planned schools (78\% ( $n=$ 25)) used the patient contact opportunity to undertake further screening and assessment including screening for anaemia (28\% of schools $(n=9))$ and recruitment for research studies $(22 \%(n=7))$. Other screening was undertaken for physical fitness $(19 \%(n=6))$, malnutrition $(16 \%$
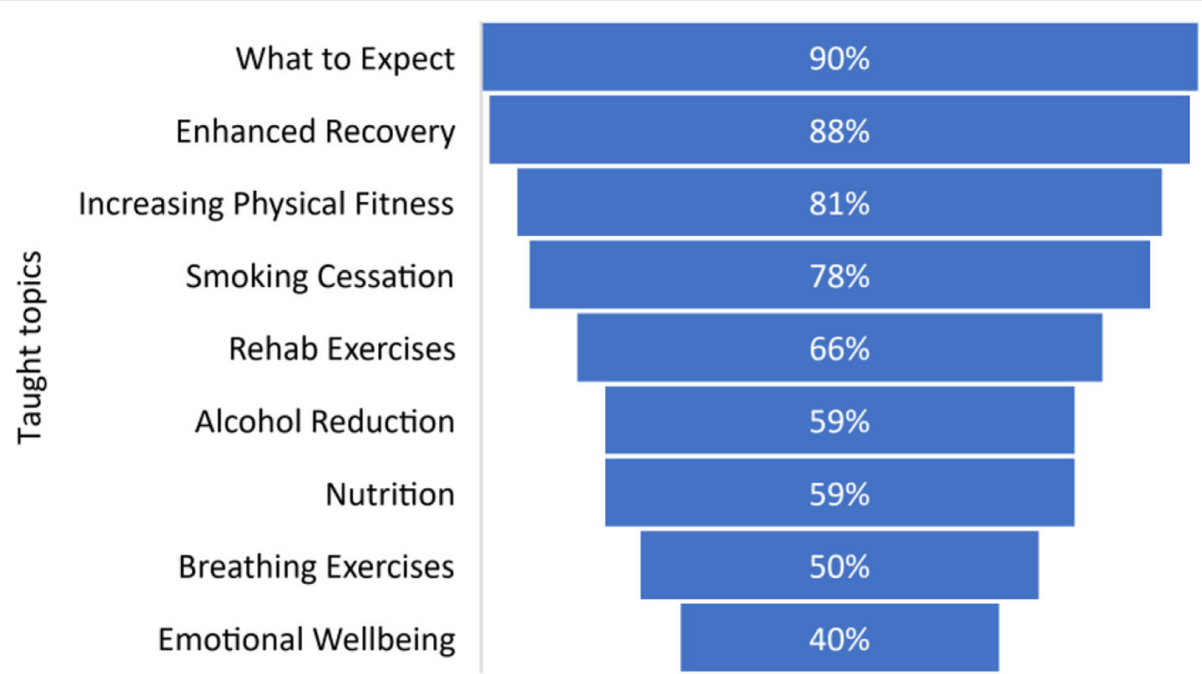

Fig. 4 Topics taught at surgery school by popularity 
$(n=5))$, anxiety $(9 \%(n=3))$, lifestyle factors $(3 \%(n=1))$ and frailty $(3 \%(n=1))$.

\section{Behaviour change support}

Respondents were asked if they offered behaviour change support as part of their surgery school. Sixtysix percent $(n=21)$ described using at least one method of support, including encouraging patients to set goals, keep diaries and use methods of communication during the session to encourage and motivate attendees.

Referral to agencies to support behavior change such as charities, gyms, council programs and smoking and alcohol cessation services was frequently described (see Fig. 5), as well as other NHS services such as dietitians, psychology and access to telephone support with session facilitators.

Just over one third of respondents of active and planned schools $(n=12)$ reported developing collaborations with local organisations to support the prehabilitation of patients including local cancer charities $(22 \%(n=7))$ and local authority programs $(16 \% \quad(n=$ 5)), see Table 1 .

\section{Outcome data}

Patient outcome data following surgery school was collected by $75 \%(n=21)$ of active schools. Fourteen percent $(n=4)$ did not collect any data, and $11 \%(n=$ 3 ) did not know if they did. Forty-three percent of active schools $(n=12)$ recorded length of hospital stay and $39 \%(n=11)$ postoperative morbidity and mortality. Other outcomes measured were postoperative data on time to drinking, eating and mobilising (25\% $(n=7))$; patient satisfaction $(21 \%$ $(n=6))$; patient-reported outcome measures $(14 \%$ $(n=4))$; and behaviour change $(7 \%(n=2))$.

\section{Future plans}

The majority of active schools $(75 \%(n=21))$ reported ambitions for the future of their surgery school which included expanding to other specialties and hospitals $(39 \%(n=11))$, developing a complete prehabilitation service $(25 \%(n=7))$ and developing online support material for patients (25\%). Others aimed to improve attendance $(18 \%(n=5))$, integrate more behaviour change interventions $(18 \%(n=5))$ and collect more outcome data $(7 \%$ $(n=2))$.

\section{Discussion}

These novel survey results provide an insightful overview of surgery school activity across the UK and Ireland and confirm growing integration of prehabilitation.

Most respondents were anesthetists or nurses with notably only one surgeon. This may be due to survey distribution bias; although ERAS UK and Centre for Perioperative Care are both multidisciplinary organisations, the membership spread across the professions is not known and preoperative optimisation tends to be anaesthetic led. Respondents reported involvement from a wide range of the MDT in the design and delivery of their schools, predominated by anaesthetists, surgeons, nurses and physiotherapists, which concurs with the published literature regarding the design and delivery of surgery schools (Moore et al., 2017; Fecher-Jones et al., 2021; Shuldham et al., 2002).

Only two (7\%) of teams involved patients in the design of their schools and $11 \%$ in the delivery. Patient

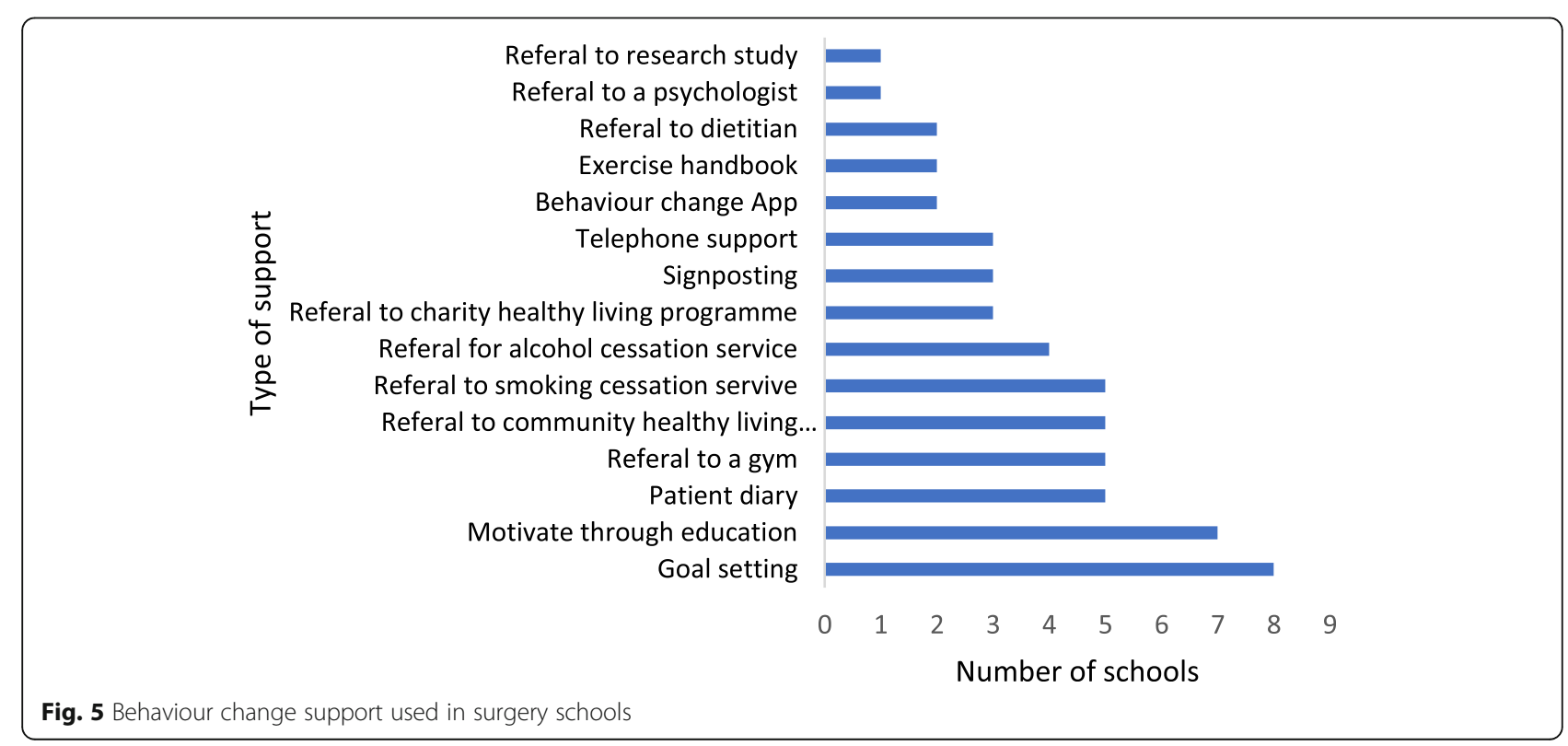


Table 1 Surgery school collaborations

\begin{tabular}{ll}
\hline Organisation & Number of schools \\
\hline Cancer charities & $7(22 \%)$ \\
Local authorities & $5(16 \%)$ \\
Local gyms & $2(6 \%)$ \\
Research studies & $2(6 \%)$ \\
Sports charities & $1(3 \%)$ \\
Universities & $1(3 \%)$ \\
\hline
\end{tabular}

participation in the design, delivery and evaluation of new services has been found to enhance service delivery and acceptability (Bombard et al., 2018). Service users are also key stakeholders in any intervention that aims to change behavior (NICE, 2014). Surgery schools aim to empower patients and their support network to take an active role in planning and preparing for their operation (Royal College of Anaesthetists, 2017); therefore, their role in the planning and design phase of the school is important if it is to achieve its aim.

To our knowledge, there is only one example in the published literature of utilising patient and family input to support the design of surgery schools and other education-based resources (Moore et al., 2017). This concurs with the low number of respondents to the current survey describing such involvement. However, a significant number of respondents reported working with local organizations and explicitly cancer charities, which would help recognise the needs of patients and their families. Considering local patient and family participation in surgery school design and implementation is recommended for future services.

Most of the schools aimed to support patients to increase their physical activity and/or make healthful dietary changes, yet only two reported psychologist involvement, and none recount involvement of a behaviour change specialists in the design of the schools. The design of behaviour change interventions should be evidence-based, patient-focused and delivered by teams with core skills, knowledge and competence in behaviour change techniques (NICE, 2014). Over half of the respondents reported using methods to help motivate and facilitate patients' behaviour change but were unable to link these with evidenced-based behavior change techniques (Michie et al., 2013). This suggests a lack of knowledge of behavior change models and techniques and supports the case for behavior change specialists to be involved in surgery school design.

One third of the respondents reported working collaboratively with local agencies such as charities and local authorities to support patients to make lifestyle changes. Identification and signposting to support networks is critical if behaviour change is to be achieved (NICE, 2014; Grimmett et al., 2021). It is well evidenced that many people will require more than just instruction to change behaviour. More intensive personalised support may be required in order to make and sustain lifestyle behaviour changes (Grimmett et al., 2019).

The notable increase in the numbers of new schools in the last 2 years reflects the growing interest in prehabilitation particularly for cancer (Macmillan, 2019) and the ability to integrate aspects of this into surgery school curriculums as a universal intervention for all surgical patients. Respondents also reported visiting other surgery schools within the UK which they encouraged. Visiting and talking to other clinicians about their surgery school appears to promote shared learning and prevents teams from 'reinventing the wheel'. It may however have limited the development of different models of surgery school. Indeed, the schools described in this survey appear very similar, with most lasting 1 to $2 \mathrm{~h}$, organised as a one-off session and attended by $5-20$ patients at a time. Surgery schools were generally offered to a wide range of surgical specialties, although notably absent was cardiac surgery, which was unexpected given there are published studies demonstrating the benefit of group education on the clinical outcomes of cardiac patients (Shuldham et al., 2002; Goodman et al., 2008). It is also noted that $40 \%(n=11)$ of the active schools were Orthopaedic. These 'Joint schools' were more likely to be longer established but less likely to include elements of prehabilitation. This is supported by the literature, where joint schools are commonly described as standard care prior to joint surgery, often delivered by nurses and surgeons with more of a focus on rehabilitiation than prehabilitiation (McDonald et al., 2014).

Most schools taught similar topics, with emphasis on enhanced recovery and patient expectation management of major surgery. Prehabilitation components were also common, including increasing physical activity taught by $81 \%$ of schools and preoperative nutrition taught by $59 \%$ of schools. Support for psychological wellbeing was included in just $40 \%$ of schools, despite being a key component of trimodal prehabilitation (Li et al., 2013), and with evidence that poor preoperative psychological health is associated with poorer outcomes (Rosenberger et al., 2006; Kitagawa et al., 2011). However, research in this area is in its infancy, with an urgent need for highquality trials investigating the impact of preoperative psychological support (Levett \& Grimmett, 2019). Although preoperative nutrition was taught by two thirds of the schools, only $25 \%$ listed a dietitian as part of their design team, compared with $78 \%$ schools who listed physiotherapists. This is despite convincing evidence that preoperative malnutrition is associated with a worse postoperative outcome (Gillis \& Wischmeyer, 2019).

The majority of schools supplemented teaching with additional learning resources with most offering 
bespoke, locally written information. Less than $20 \%$ ( $n=$ 6) reported using nationally available patient information such as the Royal College of Anaesthetists 'Fitter Better sooner' guide (Royal College of Anaesthetists, 2017), perhaps suggesting that the national documentation does not quite fit local requirements. It has been argued that written documentation is often ineffective in communicating information due to issues with readability and accessibility (Zorn MaR, 2000). Evidence suggests that between 43 and $61 \%$ of English working age adults routinely do not understand health information due to low health literacy (Rowlands et al., 2015). In relation to prehabilitation, there is a strong association with health literacy and physical exercise; the higher the health literacy, the higher the frequency of physical exercise. It is also known that patients with lower health literacy have more difficulty in planning and adjusting their lifestyle to maintain good health (Wittink \& Oosterhaven, 2018). Web- and phone-based apps have been found to be an effective way of delivering health information tailored to individuals with limited health literacy (Kim \& Xie, 2015). Results from our survey found that only three respondents reported using apps, but many mentioned them in their future ambitions.

Although the majority of respondents reported their schools to be NHS funded, only $25 \%$ of these charged a tariff (an agreed price for an individual service). Some Trusts may receive 'block payments' based on an agreed payment for the provision of a service rather than individual payment per appointment or episode. Funding surgery schools is anecdotally a challenge. We found that some teams were delivering schools in their own unpaid time. Under half of respondents had secured long-term funding. Group education sessions are a costeffective way of information giving to patients (Seesing et al., 2014) and may reduce the outpatient time needed. Given their potential for reducing surgical complications and length of stay, they may present an attractive cost improvement opportunity for organisations. However, the limited evidence base for the efficacy of surgery schools may provide an explanation as to why organisations are hesitant to commit to funding.

Seventy five percent of respondents reported collecting outcome data; however, postoperative length of stay and morbidity and mortality were collected by fewer than half of the teams, and behaviour change by only $7 \%$. Without these as markers of clinical effectiveness, sustaining the service within the current financial climate is likely to be difficult. Given the additional staffing resources that are often needed to collect robust prospective data, there is a need for standardisation of a minimum dataset, including measures of behavior change, length of hospital stay, post-operative morbidity as well as patient-reported outcome measures. Data collection tools are also needed to facilitate this practice. Including a patient education category within national perioperative audit datasets such as The Perioperative Quality Improvement Project (Health Services Research Centre Perioperative Quality Improvement Project (PQIP), 2019) would be one way of doing this.

This survey was conducted before the COVID-19 pandemic, which resulted in face-to-face group education no longer being an option due to the risk of virus transmission. Five of the centres who took part in this survey have subsequently contacted the authors and report moving their surgery schools to online group sessions in recent months. The findings of this survey therefore remain highly relevant regarding the future of group preoperative education whether it be delivered virtually or face-to-face. The pandemic has also resulted in a back$\log$ of patients awaiting surgery, thus creating an extended window of opportunity for patients to improve their fitness for surgery through lifestyle modification. Surgery school provides a likely cost-effective platform for perioperative clinicians to support patients to use this time proactively which should not be overlooked.

\section{Strengths and Limitations}

This survey provides the first published window of insight into surgery schools across the UK, establishes a baseline of clinical activity and identifies the similarities and differences between schools. Capturing this has enabled us to identify clear suggestions for practice and research that will underpin the future of surgery schools.

Although 80 clinicians responded to the survey only, 32 different schools were identified, which equates to $9 \%$ of 356 UK hospitals undertaking surgery having a surgery school (National Audit Project (NAP), 2021). We acknowledge that the actual number of surgery schools in the UK will likely be higher and that there may be bias in responses by nature of the fact that those with an interest surgery schools were more likely to take part. It was also noted that although responses were from across the UK and Ireland, they were most commonly from larger centres within UK cities, and almost a third were from London and the South of England. This bias may be due to those centres having more established perioperative services. The reasons for the large number of responses with missing data are also not known. It would have been useful to include within the survey a question asking whether respondents had a surgery school. A response of 'no' would have justified missing data. Responses to the open questions varied considerably in length and depth. This may have been because some respondents had more time or insight into the detail of their surgery school than others, but none the less will have influenced the overall findings. 


\section{Suggestions for practice and research}

Future priority is to establish the clinical effectiveness of surgery school. This relies on teams and organisations working together to standardise their data collection and publish their outcomes. Data collection of outcomes needs to be considered within service development plans and adequately resourced. The recently completed Greater Manchester Implementation of 'ERAS+' will provide useful information about the effectiveness of surgery school (The Health Foundation, 2020).

Teams aiming to change patient behaviour should involve service users in the design of their programmes as well as evidence-based techniques for supporting behavior change.

Health literacy of participants should be considered from the outset to ensure accessibility of surgery school for all patient participants and the most appropriate supporting resources.

\section{Conclusion}

Surgery schools are a growing phenomenon in the NHS and provide education on a range of topics to patients and their families prior to major elective surgery. Schools provide a platform for introducing the elements of prehabilitation and the potential for motivating behaviour change. Inclusion of behavioral science and patients within the design of these interventions would maximise the effectiveness of schools in promoting behaviour change. Funding remains the biggest threat to the future of these schools, and without comprehensive collection of clinical effectiveness outcome measurements, and dissemination of the results, the future is uncertain. The authors challenge teams to think creatively, particularly around this time of uncertainty within the NHS, to establish collaborations with external agencies and focus on developing and sharing resources to improve access for all patients to this type of education.

\section{Abbreviations}

ERAS: Enhanced Recovery after Surgery; NHS: National Health Service; MDT: Multidisciplinary team; BCT: Behaviour change technique

\section{Supplementary Information}

The online version contains supplementary material available at https://doi. org/10.1186/s13741-021-00188-2.

Additional file 1. Survey questions

\section{Acknowledgements}

The authors would like to thank Prof. M Grocott, Mrs J. Murfin, the ERAS UK Society, the Perioperative Exercise Testing and Training Society (POETTS) and Centre for Perioperative Care for their help and support with this survey. This paper was published on behalf of the Perioperative Exercise Testing and Training Society (POETTS).

\section{Authors' contributions}

IFJ_-primary researcher, drafted paper, primary data collector and analyst. CG_-substantial contribution through feedback of design, review of content. FJC, DHC, DZHL, JAM—substantial contribution with regard to content review and feedback on design. All authors read and approved the final manuscript.

\section{Funding}

IFJ is an ICA Pre-doctoral Clinical Academic Fellow supported by Health Education England and the National Institute for Health Research

Availability of data and materials

All survey data is available from the corresponding author on reasonable request.

\section{Declarations}

Ethics approval and consent to participate

Not required

Consent for publication

Not applicable

Competing interests

The authors declare that they have no competing interests.

\section{Author details}

${ }^{1}$ University Hospital Southampton NHS Foundation Trust, Southampton SO16 6YD, UK. ${ }^{2}$ School of Health Sciences, University of Southampton,

Southampton, UK. ${ }^{3}$ Enhanced Recovery After Surgery (ERAS) UK, 4 Aldon

House, Yeovil, UK. ${ }^{4}$ Manchester University NHS Foundation Trust, Manchester, UK.

Received: 25 September 2020 Accepted: 16 April 2021

Published online: 15 June 2021

\section{References}

Bombard Y, Baker GR, Orlando E, Fancott C, Bhatia P, Casalino S, et al. Engaging patients to improve quality of care: a systematic review. IS. 2018;13(1):98.

Dawson S. Principles of preoperative preparation. In: Manley K, Bellman L, editors. Surgical nursing: advancing practice. 1st ed. Edinburgh: Churchill Livingstone; 2000. p. 386-407.

Fecher-Jones I, Grimmett C, Edwards MR, Knight JS, Smith J, Leach H, Moyses H, Jack S, Grocott MPW, Levett DZH Development and evaluation of a novel pre-operative surgery school and behavioural change intervention for patients undergoing elective major surgery: Fit-4-Surgery School. Anaesthesia. 2021. doi: https://doi.org/10.1111/anae.15393. Epub ahead of print. PMID: 33538015.

Gillis C, Wischmeyer PE. Pre-operative nutrition and the elective surgical patient: why, how and what? Anaesthesia. 2019;74(Suppl 1):27-35. https://doi.org/1 0.1111 /anae.14506

Giraudet-Le Quintrec JS, Coste J, Vastel L, Pacault V, Jeanne L, Lamas JP, et al. Positive effect of patient education for hip surgery: a randomized trial. Clin Orthop Relat Res. 2003;414:112-20. https://doi.org/10.1097/01.blo.00000792 68.91782.bc.

Goodman H, Parsons A, Davison J, Preedy M, Peters E, Shuldham C, et al. A randomised controlled trial to evaluate a nurse-led programme of support and lifestyle management for patients awaiting cardiac surgery 'Fit for surgery: Fit for life' study. Eur J Cardiovasc Nurs. 2008;7(3):189-95. https://doi. org/10.1016/j.ejcnurse.2007.11.001.

Grimmett C, Bradbury K, Dalton SO, Fecher-Jones I, Hoedjes M, Varkonyi-Sepp J, et al. The role of behavioral science in personalized multimodal prehabilitation in cancer. Front Psychol. 2021;12:261.

Grimmett C, Corbett T, Brunet J, Shepherd J, Pinto BM, May CR, et al. Systematic review and meta-analysis of maintenance of physical activity behaviour change in cancer survivors. Int J Behav Nutr Phys Act. 2019;16(1):37. https:// doi.org/10.1186/s12966-019-0787-4.

Health Services Research Centre Perioperative Quality Improvement Project (PQIP). Available from: www.pqip.org.uk/content/home [Accessed 3 August 2019) 
Kim H, Xie B. Health literacy and internet- and mobile app-based health services: a systematic review of the literature. Proceed Assoc Inform Sci Technol. 2015; 52(1):1-4.

Kitagawa R, Yasui-Furukori N, Tsushima T, Kaneko S, Fukuda I. Depression increases the length of hospitalization for patients undergoing thoracic surgery: a preliminary study. Psychosomatics. 2011;52(5):428-32. https://doi. org/10.1016/j.psym.2011.03.010.

Levett DZH, Grimmett C. Psychological factors, prehabilitation and surgical outcomes: evidence and future directions. Anaesthesia. 2019;74(Suppl 1):3642. https://doi.org/10.1111/anae.14507.

Li C, Carli F, Lee L, Charlebois P, Stein B, Liberman AS, et al. Impact of a trimodal prehabilitation program on functional recovery after colorectal cancer surgery: a pilot study. Surg Endosc. 2013;27(4):1072-82. https://doi.org/10.1 007/s00464-012-2560-5.

Macmillan. Prehabilitation evidence and insight review 2017 Available from: www.macmillan.org.uk/_../prehabilitation-evidence-and-insight-review_ tcm9-335025.pdf. [Accessed 12 September 2019]

McDonald S, Page MJ, Beringer K, Wasiak J, Sprowson A. Preoperative education for hip or knee replacement. Cochrane Database Syst Rev. 2014;2014(5):1-68.

McGregor AH, Rylands H, Owen A, Dore CJ, Hughes SP. Does preoperative hip rehabilitation advice improve recovery and patient satisfaction? J Arthroplasty. 2004;19(4):464-8. https://doi.org/10.1016/j.arth.2003.12.074.

Mezzanotte EJ. Group instruction in preparation for surgery. Am J Nurs. 1970; 70(1):89-91.

Michie S, Richardson M, Johnston M, Abraham C, Francis J, Hardeman W, et al. The behavior change technique taxonomy ( $v 1)$ of 93 hierarchically clustered techniques: building an international consensus for the reporting of behavior change interventions. Ann Behav Med. 2013;46(1):81-95. https://doi.org/10.1 007/s12160-013-9486-6.

Moore J, Merchant Z, Rowlinson K, McEwan K, Evison M, Faulkner G, et al. Implementing a system-wide cancer prehabilitation programme: the journey of Greater Manchester's 'Prehab4cancer'. Eur J Surg Oncol. 2020.

Moore JA, Conway DH, Thomas N, Cummings D, Atkinson D. Impact of a perioperative quality improvement programme on postoperative pulmonary complications. Anaesthesia. 2017;72(3):317-27. https://doi.org/10.1111/anae.13763.

National Audit Project (NAP) Anaesthesia, surgery and life-threatening allergic reactions RCoA 6th National Audit Project: Perioperative Anaphylaxis 2018. Available from: https://www.nationalauditprojects.org.uk/downloads/NAP6\%2 OReport\%202018.pdf [Accessed 30 March 2021)

Nepogodiev D, Martin J, Biccard B, Makupe A, Bhangu A, National Institute for Health Research Global Health Research Unit on Global S. Global burden of postoperative death. Lancet. 2019;393(10170):401.

NICE. Behaviour change: individual approaches public health guideline [PH49] NICE; 2014 Available from: https://www.nice.org.uk/guidance/ph49. [Accessed 4 March 2019]

Rosenberger PH, Jokl P, Ickovics J. Psychosocial factors and surgical outcomes: an evidence-based literature review. J Am Acad Orthop Surg. 2006;14(7):397405. https://doi.org/10.5435/00124635-200607000-00002.

Rowlands G, Protheroe J, Winkley J, Richardson M, Seed PT, Rudd R. A mismatch between population health literacy and the complexity of health information: an observational study. Br J Gen Pract. 2015;65(635):e379-e86. https://doi.org/10.3399/bjgp15X685285

Royal College of Anaesthetists. Fitter Better Sooner. 2017 Available from: www. rcoa.ac.uk/patient-information/preparing-surgery-fitter-better-sooner [Accessed 9/6/2019)

Seesing FM, Drost G, Groenewoud J, van der Wilt GJ, van Engelen BG. Shared medical appointments improve QOL in neuromuscular patients: a randomized controlled trial. Neurology. 2014;83(3):240-6. https://doi.org/1 0.1212/WNL.0000000000000588.

Shuldham CM, Fleming S, Goodman $\mathrm{H}$. The impact of pre-operative education on recovery following coronary artery bypass surgery. A randomized controlled clinical trial. Eur Heart J. 2002;23(8):666-74. https://doi.org/10.1053/ euhj.2001.2897.

Survey Monkey. Available from: surveymonkey.co.uk [Accessed 2 June 2019]

The Health Foundation. Available from: https://www.health.org.uk/improvementprojects/improving-surgical-care-for-patients-and-their-families-in-greater-ma nchester-\%E2\%80\%93. [Accessed 3 August 2020)

Wittink $\mathrm{H}$, Oosterhaven J. Patient education and health literacy. Musculoskelet Sci Pract. 2018;38:120-7. https://doi.org/10.1016/j.msksp.2018.06.004.

Zorn MaR, S.. Health risk communication In: Medicine NLo, editor. Current bibliographies in medicine 2000. Bethesda, MD.2000.

\section{Publisher's Note}

Springer Nature remains neutral with regard to jurisdictional claims in published maps and institutional affiliations.
Ready to submit your research? Choose BMC and benefit from:

- fast, convenient online submission

- thorough peer review by experienced researchers in your field

- rapid publication on acceptance

- support for research data, including large and complex data types

- gold Open Access which fosters wider collaboration and increased citations

- maximum visibility for your research: over $100 \mathrm{M}$ website views per year

At $\mathrm{BMC}$, research is always in progress.

Learn more biomedcentral.com/submissions 